\title{
CONTRIBUCIONES A LA ALEGRÍA Y A LA JUSTICIA EPISTÉMICA, CON TODA SERIEDAD
}

\author{
Contributions to the Joy And the Epistemic Justice, in EArnest \\ María Luisa de la Garza Chávez* \\ DOI: http://dx.doi.org/10.29043/liminar.v19i2.866
}

Resumen: Reseña de La danza de la insurrección. Para una sociología de la música latinoamericana. Textos reunidos de Ángel G. Quintero Rivero (1978-2017). Buenos Aires: Consejo Latinoamericano de Ciencias Sociales, 2020.

Abstract: Review of La danza de la insurrección. Para una sociología de la música latinoamericana. Textos reunidos de Ángel G. Quintero Rivero (1978-2017). Buenos Aires: Consejo Latinoamericano de Ciencias Sociales, 2020.

E laño pasado, 2020, el Consejo Latinoamericano de Ciencias Sociales publicó uno más de sus Legados CLACSO, con textos de Ángel G. Quintero Rivera, al que tituló La danza de la insurrección. Para una sociología de la música latinoamericana. Hay que celebrarlo, entre otros motivos porque muestra al querido y gran "Chuco" - como le dicen sus amigos - en toda su robusta densidad, pues se trata de un sociólogo con pasión por la historia, la filología, la demografía y la economía —además de la música y el baile, claro-; que acude a fuentes primarias y secundarias, que hace mucho trabajo directo con los protagonistas y mucho trabajo de archivo; que dialoga, siempre de forma respetuosa y aguda, con otros colegas; que consistentemente hace balances críticos y análisis metarreflexivos, pero siempre con modestia y sencillez.

Antes de entrar propiamente a los textos que conforman esta Antología, hay que destacar su escritura, que diría es de enorme tacto, por la sensibilidad que desde sus primeros trabajos manifiesta en relación, por

\footnotetext{
* María Luisa de la Garza Chávez. Doctora en Filosofía y Diplomada en Estudios Avanzados en Antropología Social y Cultural, por la Universidad Autónoma de Madrid, España. Docente-investigadora en el Centro de Estudios Superiores de México y Centroamérica de la Universidad de
}

ejemplo, con las inequidades de género o la conciencia de irreversibilidad que implican algunos procesos vitales, pero también por tener siempre presentes las tensiones entre lo comunitario, lo nacional y lo global y no olvidar nunca la posición relativa de todo punto de vista. Además, su gusto por la etimología y otros detalles lingüísticos lo llevan, por un lado, a ser muy preciso y, por otro, a apelar con frecuencia a significados compartidos, lo que parecería favorecer la empatía del lector.

La escritura de Ángel Quintero, profesor del Centro de Investigaciones Sociales de la Universidad de Puerto Rico, contiene la fuerza y la ternura de la esperanza, porque desde sus primeros textos mira la realidad circundante buscando, no importa lo difícil y crudo que sea el tema, una alegría, una fisura en el sistema, un desafío mediante la creatividad y el ingenio, unas claves libertarias, con el doble sentido de clave sincopada característica de las "músicas mulatas" que son práctica de resistencia, y de elementos histórico-

Ciencias y Artes de Chiapas (CESMECA-UNICACH), México. Correo electrónico: mluisa_delagarza@yahoo.es. ORCID: 0000-0001-5224-4726.

Recibida: 15 de marzo de 2021

Aprobada: 29 de mayo de 2021 
sociales que explicarían gestos contestatarios de las clases subordinadas.

Quintero busca de algún modo coadyuvar a revertir la desvaloración de los profundos saberes afro, y por ello recopila saberes y nociones en torno al saber mismo, al tiempo que les da visibilidad a las estrategias - con frecuencia camufladas - con las que los subordinados desafían cotidianamente un orden social que los tiene sojuzgados, excluidos, y en otro tiempo los tuvo esclavizados.

Después de unos "Apuntes preliminares" en los que Quintero narra su trayectoria intelectual (partiendo de aquel viaje que realizara a Inglaterra para estudiar la Maestría "gracias a las gestiones de un rector progresista de la Universidad de Puerto Rico" (p. 1l), noble mención que es a la vez agradecimiento y alerta en favor del impulso a jóvenes con vocación de investigadores), abre la Antología con "Socialista y tabaquero. La proletarización de los artesanos”, un trabajo en la línea de los estudios culturales que había aprendido en Birmingham, pero donde ya se aprecia con toda claridad una preocupación que podría definir toda su obra: la herencia cimarrona en las utopías libertarias - en este caso obreras- Se trata de un texto extenso y profundo que aborda la transformación de los artesanos tabaqueros - mayoritariamente negros o mulatos que eran productores independientes - en proletarios; esto en el cambio del siglo XIX al XX, en un Puerto Rico que recién había abolido la esclavitud y que sufrió la invasión norteamericana en 1898.

Esta investigación indaga en la relación de estos artesanos tabaqueros con los de otros oficios, así como con los hacendados y, de forma muy importante, con los comerciantes y profesionistas, con quienes compartían la vida urbana. En sus páginas conocemos los procesos sociales que dieron lugar a las organizaciones gremiales, así como las transformaciones que impuso el crecimiento de la industria de la manufactura del tabaco, que subvirtió el modo de producción artesanal al imponer una "innovadora" y cada vez más rígida y atomizada división del trabajo, aunque también influyeron las transformaciones económicas generadas por la invasión norteamericana, que favorecieron la implantación de esos entes jurídicos "impersonales" denominados corporaciones. En este sentido, atestiguamos las razones y los modos en los que los antiguos artesanos se hicieron sindicalistas.

En el conjunto de amplios datos estadísticos contrapunteados con análisis socioculturales, resulta particularmente interesante la "tradición de la parejería”, esa actitud de la cimarronería que manifestaba irreverencia a la jerarquía social y buscaba colocarse "en niveles asignados por la cultura dominante a los estratos sociales supuestamente 'superiores"' (p. 39), consiguiéndolo notablemente en el ámbito musical y en el ámbito de la filosofía política. Al parecer, los artesanos tabaqueros "vivieron en forma mucho más intensa que los hacendados las discusiones y nuevas corrientes del mundo intelectual internacional" (p. 40), y llegaron a impulsar tres movimientos racionalistas que a la postre resultarían inaceptables tanto para el hacendado y su ideología señorial, como para los comerciantes, que vieron en entredicho sus privilegios económicos y políticos: la liberación de la mujer, el ateísmo y el socialismo libertario. A cada uno de estos movimientos dedica el maestro Quintero unas entrañables páginas.

El segundo texto, "Del canto, el baile... y el tiempo", es la primera parte del celebérrimo iSalsa, sabor y control! Sociología de la música "tropical", un texto que, "estrictamente hablando", no formaba parte de un libro sobre música, pues lo que Quintero pretendía era abordar, a través del análisis de las relaciones entre una sociedad y sus expresiones sonoras, "las sutilezas y complejidades de la dinámica histórica de las identidades colectivas" (p. 88), es decir, la forma como se han ido constituyendo en el Caribe unas formas específicas de sociabilidad. Ahora bien, el capítulo, en esta edición, aparece con unos párrafos introductorios nuevos, que de alguna manera cobijan la Antología entera y que remiten al deseo, retomado de cierta confesión del sociólogo haitiano Gerard Pièrre Charles, de que la academia, además de abordar los acontecimientos terribles que se suceden periódicamente en el Caribe, sea capaz de ver también las contribuciones del Caribe a la alegría del mundo, y, ya puestos, "lo que nos dice el 
estudio de las contribuciones del Caribe a la alegría del mundo sobre el postindustrialismo o la globalización" (p. 86). Hay que destacar que no solo se trata de que las bibliografías de los distintos capítulos hayan sido actualizadas con referencias a trabajos posteriores a 1998, año de la primera publicación de Salsa..., sino que en varios momentos hay una actualización de los propios textos, con algunas pocas pero significativas inserciones, como esta.

La ocasión de reseñar una compilación que incluye este texto tan conocido y trabajado en toda América Latina me permite referir dos lecturas erráticas que suelen hacerse desde estas tierras continentales con formas de sociabilidad históricamente diferentes a las caribeñas: la primera es la dificultad de comprender hasta qué punto un bailador o una bailadora puede guiar a los músicos, si no se conocen prácticas musicales como la de la bomba puertorriqueña, en la que el tambor primo o subidor debe seguir, literalmente, al bailador o a la bailadora, en un diálogo que está compuesto de elegantes desafíos producidos por los movimientos del cuerpo y, en el caso de las bailadoras, también de la falda de amplias enaguas. Hasta que uno no ve con sus propios ojos (aunque sea a través de YouTube) lo que esto significa en realidad, nos resulta inconcebible, y el texto de Quintero da la impresión de ser un poco exagerado. Por ello, si solo se hace la lectura de este capítulo - o incluso del libro entero-, recomiendo acercarse a ver la práctica dancística para comprender el texto a cabalidad.

La segunda lectura equívoca es lo que nos evoca la palabra "control" del título, pues teniendo -en general - más presente a Foucault —o a las fuerzas del orden- que a los soneros y salseros caribeños, quienes se extienden en el canto antifonal y manejan formas rítmicas múltiples y abiertas, no comprendemos que "sabor y control" alude a una frase que fue habitual en los comienzos de la salsa y que sintetizaba el desplazamiento pendular entre una parte musical rápida e intensa y otra más suave, más contenida, más controlada. Sé que no he sido la única que, en una primera lectura, también sintió que alguna expectativa a este respecto no se había cumplido, pese a que el libro es enfático en las diversidades rítmicas y temporales... Eso sí, una vez rebasados los límites de lo pensable, se modifica también la escucha, y uno se descubre tratando de descifrar auditivamente alguna de las muchas cosas aprendidas, consiguiendo - acaso - distinguir la parte suave de la pieza, de la más intensa.

El baile vuelve a ser el tema central de los capítulos quinto y sexto; el primero de ellos, "Los modales del cuerpo. Clase, raza y género en la etiqueta del baile", tiene entre sus ejes de desarrollo el Manual de urbanidad y buenas maneras, de Manuel Antonio Carreño Muñoz (sí, ha leído usted bien, el "Manual de Carreño"), el cual al parecer respondió a la necesidad de los patricios caribeños (su autor era venezolano) de codificar los modales de la "plantocracia hacendada", con la doble intención de parecerse a sus "iguales" europeos y de distinguirse de sus dominados, mulatos y negros (decimos "dominados" y no subordinados porque cuando el Manual se publicó por primera vez, en 1853, aún no se había abolido la esclavitud en Venezuela —ni en otros países del Caribe, como Puerto Rico- y es el tratamiento que le da Quintero.)

Aunque el cuerpo y los movimientos corporales son fundamentales en el Manual, este no dedica ninguna de sus edificantes páginas específicamente al baile, pues esta actividad era considerada propia de la población a la que no iban dirigidas sus reglas de etiqueta. Sin embargo, viene a colación porque su redacción fue parte de un esfuerzo por construir una cultura cívica ("moderna" y "civilizada") distinta al orden colonial metropolitano, esfuerzo en el que se vivieron paradójicas y sutiles tensiones, no solo porque hubo mulatos y negros libres que tuvieron una participación fundamental en la conformación de esta cultura a nivel político, sino porque la polirritmia y los propios tambores de ascendencia africana fueron colándose —camuflados en los instrumentos melódicos-en los más distinguidos casinos y salones.

Así, entre ilustradores apartados sobre la distinción entre danza y baile, entre contradanza europea y danza puertorriqueña, o entre mujer bailada y mujer bailadora, volvemos a saber de históricas medidas de censura a la manifestación corporal de las emocio- 
nes - muy específicamente, a la libertad gestual de las mujeres-, y no podemos sino evocar polémicas de gran actualidad cuando leemos las indignadas reacciones ante la expansión, a mediados del siglo XIX, de una "danza moderna" que "sólo expresa[ba] la pasión amorosa" y que, pese a haber sido prohibida por el gobernador de Puerto Rico en 1849, la gente de todas las clases sociales seguía cultivando esa "moda perniciosa" y "predisponente", como se lee en una de las varias perlas bibliohemerográficas que Quintero nos comparte acerca del que acabaría siendo baile nacional (perla procedente, en este caso, de El campesino puertorriqueño, un texto de 1887 de F. del Valle Atiles).

Si el capítulo sobre los modales del cuerpo se enfoca en ese umbral entre lo público y lo privado que atañe al baile como forma de relación interpersonal, "Baile y ciudadanía" apunta, más ampliamente, hacia la pertenencia social, a las relaciones comunales, a partir del análisis de algunas músicas rituales y populares, en especial de la bomba ya referida, esa música-baile que es comunicación ancestral entre personas de grupos humanos que vivieron, en tiempos de la esclavitud, la privación de la palabra.

Quintero se refiere a la formación cultural caribeña como "descentrada" porque, determinada por las contradicciones dialécticas del sistema de plantación y contraplantación, de esclavitud y cimarronería, tiene una hibridez y una heterogeneidad que chocan con la modernidad occidental y sus nociones fundamentales, una de ellas la dicotomía mente/cuerpo. Por ello, pone en valor formas de hacer música donde la expresión individual solo florece en la solidaridad comunal, donde la heterogeneidad de tiempos superpuestos en la polirritmia evidencia una racionalidad diferente de la que no puede escindirse lo corporal-, y donde los movimientos "descentrados" o "policéntricos" de mulatos y negros se distancian del torso rígidamente erecto del tradicional practicante de ballet, e incluso de la danza vuelta coreografía.

Este mundo musical y danzante afroamericano contendría, a la vez que propiciaría, una estructura sentimental y política diferente, al otorgarle valor a la heterogeneidad, a lo indeterminado, a lo abierto y a lo múltiple, horadando "brechas democratizantes anticoloniales en el terreno de la hegemonía” (p. 419). Desde la perspectiva de Quintero, el "diálogo tenso (a-sistémico) entre melodía, armonía y ritmo, y entre las distintas partes del cuerpo danzante, [así como] la combinación del sentido dramático de la canción con la apertura improvisatoria de los soneos, repiqueteos y descargas, [sumados a la reunión de] el canto con el baile y, concomitantemente, la composición con la improvisación, lo conceptual estructurado con la espontaneidad corporal, y la expresión individual de tipo societal con la intercomunicación comunal" (pp. 428-429) constituirían expresiones ligadas a un sentido compartido de pertenencia, que es como propone entender el término de ciudadanía, que no estaría determinado por unas obligaciones y derechos abstractos relacionados con el Estado, sino por prácticas o expresiones concretas que no solo redefinirían los parámetros de tiempo y territorio, sino que, a la vez que manifiestan cómo somos, muestran lo que hemos sido y lo que podríamos ser.

La experiencia de haber vivido en sociedades con estructuras de explotación que incluían distintos tipos de modelos esclavistas recorre toda la Antología porque es lo que subyace a la especificidad caribeña respecto del mundo moderno occidental, del cual forman (formamos) parte, pero en sus orillas. Como señala él mismo, se trata de sociedades conformadas en "los mulatos márgenes de la modernidad" (pp. 12 y 124), con culturas fuertemente cimentadas — de forma paradójica - en procesos de despojo cultural, donde al mismo tiempo que la exclusión había deferencia y paternalismo, y donde las relaciones sociales y culturales e incluso los movimientos de los poderes de los Estados estuvieron ( $\mathrm{y}$ en algunos casos siguen estando) determinados por dinámicas externas a causa de la condición -más o menos fáctica-de colonialidad.

Otros capítulos abordan el catolicismo popular en Puerto Rico en el siglo XIX, con sus máscaras, sus tallas de vírgenes y santos, sus "aguinaldos", sus cofradías y sus sorprendentes vínculos con un "blanqueamiento" cultural que buscó arraigar "lo hispano" ante la amenaza que suponían los potenciales efectos 
de la Revolución haitiana (es el caso de "Vueltita, con mantilla, al primer piso. Sociología de los santos"); o bien la transformación de una economía campesina (de estancieros y "cimarrones") a una economía agroexportadora dominada por hacendados, quienes, si bien fomentaron distinciones de clase mucho más marcadas, promovieron también -entre propietarios, artesanos y trabajadores en general - lo que comenzó a concebirse como una identidad propiamente "puertorriqueña", la cual se plasmó de manera notable en la arquitectura de localidades como Ponce. En esta ciudad, la búsqueda de singularidades individuales imprimió, paradójicamente, unidad urbanística; ahí, las plazas dejaron de lado lo militar y lo eclesiástico para constituirse en plazas de recreo; ahí, una ruralidad reconfigurada en balcones citadinos que evocaban las galerías de una hacienda fue vista nada menos que como símbolo de modernidad; y, desde ahí, emergió una "cultura nacional señorialmente hegemonizada” (p. 303) que ciertamente integraba, pero sin alterar la estratificación (en "Ponce: la capital alterna. Sociología de la sociedad civil y la cultura urbana en la historia de la relación entre clase, 'raza' y nación en Puerto Rico").

Dos son los textos que se dedican específicamente a poner en valor el significado histórico, el peso simbólico y la experiencia encarnada de "lo racial". El primero de ellos, la presentación introductoria a El despertar de las comunidades afrocolombianas (María Inés Martínez, ed., La Casa y CIS-UPR, 2012) es un repaso a trabajos que fueron, poco a poco, recogiendo y resaltando la voz y las valoraciones de los propios afrodescendientes sobre sus prácticas culturales, en particular aquellas que habían quedado fuera del foco de los estudios afroamericanos por no estar vinculadas a la economía de las plantaciones. Entre otras, las experiencias de cimarronaje o las que estaban relacionadas con explotaciones mineras como las del Pacífico colombiano, contexto principal del texto que se introducía.

Estos estudios, y otros hitos hemerográficos como la revista América Negra — publicada por la Universidad Javeriana de Bogotá entre 1991 y 1998 - fueron detonantes del intercambio entre investigadores interesados en las más diversas experiencias de los afrodescendientes a lo largo y ancho del continente, y Quintero nos cuenta cómo impactaron en el reconocimiento de una cultura y una historia propias, tanto de las comunidades estudiadas como de los intelectuales afroamericanos que se dedicaron a ellas.

"La afro-historia y los Estudios Culturales decoloniales", por su parte, se enfoca en la relevancia que debería tener la afro-historia en el desarrollo de los Estudios Culturales, entendidos como esa disciplina emergente que intenta "nombrar nuevos modos de aproximación al trabajo intelectual y sus procederes analíticos" (p. 492). En efecto, después de distinguir entre los Estudios Culturales que se enfocan en la cultura producida desde lo popular y los que se enfocan en lo que el mundo popular consume (visiones tradicionalmente vinculadas a los estudios realizados en la Gran Bretaña y los Estados Unidos, respectivamente), examina la conformación de unos Estudios Culturales caribeños que, como los británicos en su momento, impulsan un proyecto político-intelectual, pero se distinguen de ellos porque tienen como cuestión central, no la producción cultural de la clase obrera, sino las trayectorias clasistas marcadas en, y determinadas por, el color de la piel.

Dice Quintero que, así "como hemos aprendido de ellos la dimensión clasista, nos toca ahora enseñarles desde unos Estudios Culturales afro-diaspóricos" (p. 498), pues la trata esclavista, la experiencia de la "migración" forzada y la propia vivencia de la esclavitud constituyen una realidad histórico-social en la que el constructo racial resulta más determinante que las relaciones de producción, ya que biologiza la otredad y le otorga un carácter irremediablemente permanente.

Se han empezado a estudiar los efectos que la experiencia afrodiaspórica pudo haber tenido en ámbitos interpersonales, sociales, políticos y culturales de la colonialidad, pero falta profundizar en muchas dimensiones. Hay "incrustaciones de africanías" — herencias de África pero también rasgos que son producto de la experiencia de la esclavitud - en las prácticas sociales de la clase obrera caribeña, y en particular parece haberlas en la cultura popular. De acuerdo con Quintero, 
los Estudios Culturales caribeños deben incorporar en sus análisis, "primero la colonialidad y dependencia, segundo el fenómeno racial como núcleo fundamental de la otredad, [...] tercero, el carácter diaspórico de su geografía y de su historia [y, cuarto,] la afro-historia de las cosmovisiones que expresan productos y prácticas estéticas" (p. 502).

Ángel Quintero aporta con su obra, de la que estos trabajos son una muestra, a la consolidación de unos Estudios Culturales "propiamente nuestros", dice, refiriéndose principalmente al Caribe insular y de la cuenca, y uno vuelve a reconocer la pluralidad de saberes de nuestra América y la pertinencia de fomentar el diálogo entre la afro-historia de América Latina y la historia de Abya Yala, pues ambas perspectivas coinciden en la necesidad de impulsar "proyectos concretos hacia la construcción de sociedades más justas y sociabilidades más enriquecedoras" (p. 440).

Para terminar, unas notas sobre la edición, pues es oportuno reivindicar la cortesía que implica, para con los lectores, que las notas estén a pie de página, que no se abrevien los nombres de los autores, que se conserven los matices introducidos por un cambio en el estilo de la fuente y que en el cuerpo del texto aparezcan, cuando se discuten unos textos concretos, sus títulos, de manera que de forma inmediata se sepa a qué obra precisa se alude.

Pese a los valores que promueve la casa editora, CLACSO, una cierta voluntad descolonial hay que impulsar también aquí, aunque debería bastar el solo deseo de claridad, sencillez y suficiencia léxica. No encuentro justificación alguna $-\mathrm{y}$ menos aún en publicaciones electrónicas - para que un paréntesis sustituya al título de una obra, llegando a absurdos tan lamentables como el del siguiente inicio de párrafo: "Es sumamente significativo cómo, según evidencian los interesantísimos y aleccionadores testimonios recogidos en (Martínez 2012), los debates en torno al uso epistemológico y político..." (p. 440, cursivas añadidas). Los testimonios interesantes, aleccionadores, aparecen sin asidero y se desvanece lo que se presentaba como "sumamente significativo".

De igual modo, al omitir el título de la obra a la que alude Quintero en la siguiente cita, la argumentación pierde referencia, pues "ese género" de cuya historia habla estaba referido en el título originalmente citado: "En su presentación al libro de Blanco, Luis Antonio Bigott recalca la importancia, para la historia de ese género central en la música del Caribe..." (p. 122, cursivas añadidas). La obra en cuestión es 80 años de son y soneros en el Caribe, 1909-1989.

Es posible que alguna extraña lógica justifique estos usos, pero debo hacer notar un error que no admite discusión: en la página 128 se ve la notación de tres claves que son distintas. Sin embargo, en esta edición la primera y la tercera son la misma transcripción. Comparando las ediciones, la primera está errada.

Salvo el último, detalles realmente menores frente a la importancia de que podamos tener libre acceso a estos textos de Ángel G. Quintero Rivera. Como en el canto antifonal, yo soy parte de un coro que hace una llamada a las generaciones nuevas para que lo lean, para que lo estudien y, con sus propios floreos rítmicos o vocales, continúen el diálogo. 